\title{
28 Resarch Square \\ Whole Exome Sequencing in Idiopathic Short Stature: rare mutations affecting growth
}

\author{
Shahab Noorian \\ Alborz University of Medical Sciences \\ Farzaneh Rohani \\ Iran University of Medical Sciences \\ Shahram Savad \\ Pars Genome \\ Kourosh Kabir \\ Alborz University of Medical Sciences \\ Nami Mohammadian Khonsari ( $\nabla$ nami.m.kh@gmail.com ) \\ Alborz University of Medical Sciences https://orcid.org/0000-0001-9218-131X \\ Nima Ghanipour \\ Alborz University of Medical Sciences \\ Mehri Gholami \\ Alborz University of Medical Sciences \\ Hooshang Zaimkohan \\ Alborz University of Medical Sciences
}

\section{Research article}

Keywords: idiopathic short stature, whole-exome sequencing, children

Posted Date: November 8th, 2019

DOI: https://doi.org/10.21203/rs.2.16842/v1

License: (c) (i) This work is licensed under a Creative Commons Attribution 4.0 International License. Read Full License 


\section{Abstract}

Introduction: one of the most common causes of referrals to paediatricians is short stature (ISS), some pathogenic mutations may present exactly similar to non-pathogenic causes, our goal is to identify and treat these patients labelled ISS with these mutations and hopefully treat them correctly.

Materials and Methods: We assessed All children under the age of fifteen years labelled as ISS. Fourteen of them were confirmed to be ISS and thus were allowed in our study. Afterwards, we pooled their blood specimens and ordered a whole-exome sequencing (WES) test.

Results: five patient had normal WES results. Four patients had rare motions that were not studied in the previous literature but due to the functions of the genes, and our patients' phenotypes it is highly possible that these mutations caused our patients' short stature. Four patients had known genetic mutations causing short stature. One patient had a mutation with no effect on height. With the help of WES, some rare mutations were found, with the patients' phenotype and evaluation we identified their function, we diagnosed some other patients' rare genetic disorders and assessed the possible effect of their mutation on their height and phenotype we aimed to determine how many children labelled as ISS are correctly diagnosed. By WES most of our patient achieved the correct diagnosis which would be impossible to diagnose without WES; thus the reason for their short stature was identified, with the correct diagnosis now we can aim for the proper treatment.

\section{Introduction}

One of the most common causes of referrals to paediatricians is short stature, a child with short stature is defined by a height that is minus two standard deviations (SD) or less than the corresponding average height for children of that age, sex, and population which may be pathologic or non-pathologic.

Due to not finding any cause and pathologies in the majority of the patients, most patients are considered to be nonpathologic, yet our goal is to identify, assess and treat children with pathologic causes, especially those who were wrongly labelled as non-pathologic. ${ }^{1-3}$. Non pathologic causes could be 1. familial that is the most seen cause of short stature and can be distinguished from pathologic causes of short stature by its normal growth velocity 4 2.Constitutional delays of growth and puberty that have a low to normal growth velocity and their growth curvature is below but parallel to the $3^{\text {rd }}$ percentile but they tend to catch up when entering puberty ${ }^{4} 3$. Idiopathic short stature (ISS) 4. Small for gestational age infants with catch-up growth, although they may have a short stature their growth usually catches up after two years of age ${ }^{5}$. As for the pathologic causes, 1 .undernutrition ${ }^{6}$ 2.systematic disease such as renal, pulmonary or cardiac impairments, metabolic disorders, endocrine conditions, etc. Come to mind. ${ }^{3,7,8}$

Other important reasons are genetic diseases with effects on growth, like Turner syndrome, Noonan syndrome, silver Russell syndrome, Short Stature homeobox (Shox) gene mutations, etc. ${ }^{9-11}$. The Differentiation of pathologic reasons from non-pathologic causes is essential, yet some pathologic causes may present exactly similar to nonpathologic causes hence their distinction is difficult. There are hundreds of different genetic variations with small effects on the height of a person ${ }^{4}$. Yet some mutations tend to greatly influence our adult height, One important example of these are shox mutations, interestingly these patients are diagnosed with ISS that nearly comprise $4 \%$ of all patients diagnosed with ISS ${ }^{1}$ Shox mutations are just one example, many monogenic disorders affect our growth with no other sign or symptom present at the time of evaluation and thus are diagnosed as ISS ${ }^{12}$. ISS is defined as a height of minus 2 SD (the FDA criterion is -2.25 SD) or more below the average for that sex and age with the absence of any diseases and underlying causes that explain the short stature ${ }^{1,2,13}$. By this definition about $80 \%$ of children 
with short stature are diagnosed with ISS due to not finding any other underlying cause ${ }^{1,14}$ yet a proper medical evaluation may result in identifying an underlying cause in up to $40 \%$ of the patients ${ }^{4}$, when a single gene mutation is suspected in a patient with short stature single gene based tests are indicated ${ }^{12}$ and these tests lead to a proper diagnosis. But what if a patient with short stature and concomitant genetic defects has no indicating phenotype, no sign and symptom of any kind? With most of them being monogenic defects as seen in many cases, how should we approach and treat these patients? Hormonal therapy Is FDA approved for treating ISS patients although treatment for all patients labelled as ISS may result in a large number of expenses for the patient and the society, not to forget some patients marked as ISS have some underlying pathologies that hormonal therapy is not advised if not contraindicated.

In patients suspected of having a genetic defect that causes short stature exome sequencing is used to determine the underlying cause. ${ }^{12}$ as reported in previous studies whole-exome sequencing (WES) in ISS patients is very useful and efficient to determine the cause of short stature ${ }^{15}$ and helps us to find monogenic mutations that greatly affected the patient's height, especially in patients that were incorrectly diagnosed as ISS due to their significant similarity that makes it almost impossible to distinguish them from one another with clinical examinations and without a proper genetic study, thus WES helps us to aim for the correct treatment and reducing all expenses.

In this study, we try to determine the efficacy of WES in the correct diagnosis of ISS patients and the cost benefits that it may have for the patient and the society and most importantly the best method for approaching a patient with ISS.

\section{Materials And Methods}

patient selection and recruitment

We assessed All children under the age of fifteen years labelled as ISS which were referred to any of our clinics (clinics under supervision of Alborz University of medical sciences) and extracted their sex, age, weight, parental heights, and past medical histories from their medical records, then we ordered routine blood tests and electrolytes and evaluated their thyroid function, growth hormone (GH) levels and Insulin-like growth factor 1 (IGF1) levels. After completion of the examinations of the initial patients and rolling out all systemic and syndromic causes of short stature, 14 of them where confirmed to be ISS and thus were allowed in our study, patients with other medical comorbidities and dimorphisms were included in the study as long as these other conditions had no relation to their short stature we excluded all children with intrauterine growth retardation from the study. After the approval of this study in the university's research committee and ethics in research committee of medical sciences, we explained the study to the participants and their legal guardians then a written consent was obtained from all of them.

Afterwards, we pooled blood specimens from the patients and ordered whole-exome sequencing (WES).

\section{WES}

WES was performed to enrich exons of protein-coding genes and along some other important genomic regions. Nextgeneration sequencing was performed to a sequence near to 100 million reads on illumine sequencer. The test platform was Illumina Hiseq 4000 platform conducted by Macrogen, South Korea and examined more than $95 \%$ of all targeted regions with a sensitivity above $99 \%$. This test could simultaneously detect point mutations, micro insertion and deletions and duplications less than $20 \mathrm{bp}$.

Data analysis 
we used SPSS version 19 for our data analysis, x2 And Fisher's exact test was used for comparing and categorising of means, and a $\mathrm{p}$-value of less than 0.05 was considered statistically significant.

\section{Results}

From the patients tested, only five of them had utterly normal WES results and thus were correctly diagnosed as ISS. Eight of them had mutations that indeed could be the cause of their short stature. And one patient had a mutation unrelated to his short height, thus diagnosed correctly as ISS. The mutations are shown in table 1

\section{mutations of unknown significance.}

The first patient, an eight-year-old female with a height of $112 \mathrm{~cm}$ and -2.8 SD for her age with normal height parents, was heterozygous for GHSR gene (NM_198407 exon2: c.847>T) leading to amino acid change p.R283. This gene encodes a member of the G-protein receptor family. ${ }^{16}$ although this mutation is of uncertain significance, and its inheritance could be both autosomal recessive (AR) or autosomal dominant (AD) ${ }^{16}$ pathologic mutations of this gene results in isolated partial growth hormone deficiency (GHDP) ${ }^{17}$, which result in growth delay and short stature and sometimes episodes of abdominal pain, vomiting and ketosis and hyperglycemia may accrue ${ }^{18}$. In our case this mutation of uncertain significance with its concomitance with the patient's phenotype and her low levels of $\mathrm{GH}$, we could conclude that that the mutation is likely pathologic and her short stature may be associated with this mutation.

Due to her GH levels we began hormonal therapy for her and the response was well.

The second patient a 10 year old female with a height of $112 \mathrm{~cm}$ and -4.2 for her age and a short mother with the height of $144 \mathrm{~cm}$ was heterozygous for CLCN5 gene (NM_001127898 exon14: c.2333T>G) leading to amino acid change p.L778R. This gene provides instructions for making a protein called CLC $-5{ }^{19}$ which transports chloride ions across cell membranes and plays an important role in proximal tubule cells of the kidney. It is inherited through an Xlinked recessive pattern ${ }^{19}$. Pathologic mutations of this gene are related to dent disease which is a chronic kidney disorder and is almost exclusively seen in males and results in kidney failure ${ }^{19}$. This mutation also affects serum calcium and vitamin D levels. ${ }^{20}$, it has been observed that some female carriers could manifest a few of these conditions signs and symptoms due to random X-chromosome inactivation ${ }^{21,22}$. Short stature is seen in many patients with Dent disease ${ }^{22}$. If carriers present some of these signs and symptoms of this condition, maybe our patient's short stature is the result and one of the signs of this mutation. With her mother being positive for the same mutation and its concomitance with short stature in her mother as well, it's highly likely that this mutation is the cause of her short stature.

Despite her normal GH levels we began hormonal therapy for her and the results were poor as if she was resistant to hormonal treatment Thus it could be concluded that hormonal therapy may not be indicated in this condition

The third patient a two-year-old female with short stature, microcephaly and hearing loss that is homozygous for c.395T $>G$ in exon4 of the CLPP gene (NM_006012) that are inherited through AR-pattern and is associated with Perrault syndrome type $3^{23}$. There were no studies on functional effects of this specific mutation, yet with the patient's phenotype and symptoms that are mainly seen in pathologic mutations of Perrault syndrome, likely, this mutation is also pathologic. Perrault syndrome type 3 is a rare condition that may present with different signs and symptoms and affects both male and females, a key feature of the disease is hearing loss as in our patient ${ }^{23}$. Females with this condition may have ovarian dysgenesis with normal external genitalia. Patients may also suffer from neurological conditions such as ataxia, peripheral neuropathy, and intellectual disability, ${ }^{23}$.short stature is 
another sign of this condition ${ }^{23}$.not to forget sometimes low levels of $\mathrm{GH}$ is seen in these patients ${ }^{24}$ It is highly likely that our patient's short stature with hearing loss and microcephaly resulted from Perrault syndrome. Due to our patient's low levels of $\mathrm{GH}$, we initiated hormonal therapy, but sadly, we observed no significant difference after treatment. Thus it could be concluded that hormonal therapy may not be indicated in this condition

The other patient a ten and a half-year-old male with a height of $126 \mathrm{~cm}$ and $-2.2 \mathrm{SD}$ for his age and hearing loss had three different mutations, the first one is a heterozygous variant in TMPRSS3 (NM_032404.2 exon5: c.266G>A) which leads to amino acid change p.R89H, the second one is a heterozygous variant in HOMER2 gene (NM_199330 exon3: c. $188 \mathrm{C}>\mathrm{T}$ ) that results in amino acid change p.P63L. The third one is a heterozygous variant in the FGFR3 gene (NM_001163213 exon8: c.992G>A). TMPRSS3 gene encodes a protein of serine protease family that is required for ear's saccular hair cell survival, and pathologic mutations may cause autosomal recessive deafness (DFNB8) ${ }^{25,26}$. Since it has an autosomal recessive pattern and our patient is heterozygous for this gene, it is highly unlikely as a reason for his hearing loss. The HOMER2 gene encodes a dendritic protein from the homer family and mutations in this gene may cause autosomal dominant deafness (DFNA68) a postlingual onset sensory hearing loss resulted from neural receptors damage in the inner ear ${ }^{26}$. Although the mutation in our patient is of uncertain significance due to its $A D$ inheritance and our patient's condition, this mutation is the likely cause of his hearing loss. The third gene, FGFR3 provides instructions for making a protein called fibroblast growth factor receptor 3 , mutations in this gene may cause hypochondroplasia which is a form of short-limbed dwarfism ${ }^{27}$ as seen in our patient with very mild short limbs and the predicted height for these patients range between 138 to $165 \mathrm{~cm}$ in males ${ }^{28}$ although this mutation is of uncertain significance and no studies where done on the effects of this particular mutation, due to our patients phenotype and its $A D$ pattern of inheritance it is highly probable that this mutation is the cause of his short, stature.

Although the patients $\mathrm{GH}$ levels were normal we began Hormonal therapy but the results were not as expected thus continuance of hormonal therapy for this patient is questionable.

\section{Pathologic mutations}

the first one a 5.3-year-old boy with a height of $99 \mathrm{~cm}$ and -2.2SD for his age and a short father with the height of 150 $\mathrm{cm}$ with no other medical condition was heterozygous for UROD gene (NM_000347 exon9: c. 912C>A) with an AD or AR inheritance that leads to amino acid change p.N304K.this gene provides instruction for making uroporphyrinogen decarboxylase enzyme ${ }^{29}$ and thus pathologic mutations in this gene disrupts chemical steps that leads to heme production resulting in porphyria ${ }^{30}$. There are several types of porphyria distinguished by their genetics and signs and symptoms, in our case the patients genetics was known to cause a type of porphyria similar to porphyria cutanea tarda called porphyria hepatoerythropoietic (HEP) ( that primarily effects the skin, when exposed to sun light the skin becomes fragile and blistered thus increasing the risk of infection scaring and pigmentation $)^{30,31}$, some signs and symptoms of HEP are osteolysis and shortening of distal phalanges and sclerodactyly and joint deformities that progress over time ${ }^{32}$ although at first it may seem like that this condition is not the cause of our patients short stature. Short stature can be seen in other types of porphyria (congenital erythropoietic porphyria) ${ }^{33}$ and in one case report a patient with HEP had a noticeable short stature ${ }^{34}$ although no clear path between short stature and HEP has been found due to the rarity of this disease, only very few patients are described with this condition, it seems that it's not by chance that short stature has been seen in two patients with such a rare disease, mainly when his father tested positive for this mutation and he had short stature as well, yet indeed further studies are required.

Despite the patient's normal GH levels, we began hormonal therapy, but the response was feeble thus it could be concluded that $\mathrm{GH}$ therapy in this condition is not indicated 
The second patient with a pathologic mutation was 2.6-year-old male with the height of $84 \mathrm{~cm}$ and SD of -2.2 for his age and normal height parents, was heterozygous for RYR1 gene (NM_000540 exon15: c. 1589G>A) that leads to amino acid change p.R530H and is inherited through AD pattern ${ }^{35,36}$. RYR1 provides instructions for making ryanodine receptor 1 protein that transports calcium ions and plays a critical role in muscles and movement ${ }^{35,37}$, mutations in this gene makes patients prone to malignant hyperthermia, a condition called malignant hyperthermia susceptibility $1^{38}$ especially when underwent an invasive surgery or general anesthetics ${ }^{39}$. At first it may seem like that this mutation is not responsible for our patients short stature, but on the contrary it has been observed that RYR1 gene mutation can result in short stature (King-Denborough syndrome) 40,41 to answer if this mutation is the reason of our patients short stature further studies are indicated yet we can't rule it out as a probable cause. Other coexisting conditions with our patient's condition were seizures, as previously reported in another paper we presume his seizures could be due to stress induced hyper pyrexia 42

despite the patient's normal GH levels we began hormonal therapy and we observed a well response

the third patient an 11 month year old girl with short stature and a SD of -3 for her age and normal parents was heterozygous for SMAD4 gene (NM_005359 exon 12: c. $1498 \mathrm{~A}>\mathrm{G}$ ) that leads to amino acid change p.1500V. And is of AD pattern. ${ }^{43}$ SMAD4 provides instructions for making SMAD4 protein which is part of transforming growth factor betas (TGF- $\beta$ ) signaling pathway and acts as both a transcription factor and tumor suppressor thus controlling the activity of some particular genes and preventing uncontrolled cell division and cancer. ${ }^{44,45}$ the mutation in our patient is associated with Myhre syndrome that is a condition that may result in short stature and it has a characteristic facial feature ${ }^{43,46}$ other signs and symptoms include: hearing loss, joint stiffness, limited joint mobility fibrosis, cardiovascular problems, respiratory complications, and muscular and skeletal problems. And short stature ${ }^{43,47}$. The patients' phenotype and development of the conditions mentioned above varies and depends on mutation types and domains ${ }^{43}$. In our patient beside some mild facial features and short stature abnormal TSH changes and lower normal limits of insulin-like growth factor 1 (IGF-1) was noticeable.

After GH therapy initiation at a proper age, the expected difference in her height and velocity of growth was not observed, although due to her age the response observed to treatment can not determine if hormonal therapy is indicated or not.

The other patient a two-year-old female with short stature and an SD of -2.2 and normal parents was heterozygous, for COL9A3 gene (NM_001853: exon 18:c. 920G>A) that leads to amino acid change p.G307D and is associated with multiple epiphyseal dysplasia. (OMIM 600969) ${ }^{48,49}$. And is inherited through an autosomal dominant pattern ${ }^{50}$.

Multiple epiphyseal dysplasia (MED) is a mild and variable condition in which irregular ossification of the epiphyseal cartilage occurs ${ }^{50}$. Common signs and symptoms may include early-onset arthritis, knee and hip cartilage anomalies and short stature ${ }^{49,50}$. The patient's phenotype correlated with her genotype and thus this mutation is the cause of her short stature.

Although the patient had an average level of $\mathrm{GH}$, we began $\mathrm{GH}$ therapy, but despite our best efforts, we observed a week response; thus, we might conclude that hormonal therapy in this patient is not indicated.

The last patient, a 6.9-year-old boy with a height of $99 \mathrm{~cm}$ and an SD of -4.2 for his age with normal height parents, was heterozygous for CFTR gene (NM_000492 exon11: c.1397C>G) resulting in amino acid change p.S466,and is inherited through an AR pattern, mutations in this gene may cause cystic fibrosis ${ }^{51}$ although this condition is 
inherited through an AR pattern and our patient was heterozygous for the mutation, he did not present any sign and symptom of the disease. It is highly unlikely that his short stature is related to this mutation

despite the patient's normal GH levels We began hormonal therapy and we observed a very good response to GH therapy.

The treatment results are shown in summery in table 2

\section{Discussion}

we aimed to determine how many of children labeled as ISS are correctly diagnosed and as a result of wess performed only five had absolutely no pathologic genetic mutations. By WES most of our patient achieved the correct diagnosis which would be impossible to diagnose without WES due to the rarity of their diseases and symptom presentations, thus the reason for their short stature was identified, with the correct diagnosis now we can aim for the correct treatment, when we should and shouldn't initiate GH therapy, and with the correct diagnosis we may predict possible outcomes of GH therapy and its effectiveness. Thus as seen in our study we think WES is essential and needed for the correct diagnosis of all patients labeled as ISS, not only we can find the underlying cause of their short stature we may find other diseases that their signs and symptoms hasn't started yet and we may have a chance to improve the patient's quality of live and reduce the diseases morbidity, as for the patients with short stature correct diagnosis leads to proper treatment.

\section{List Of Abbreviations}

standard deviations (SD), Idiopathic short stature (ISS)Short Stature, homeobox (Shox), whole-exome sequencing (WES), Insulin-like growth factor 1 (IGF1), isolated partial growth hormone deficiency (GHDP), autosomal recessive deafness (DFNB8), autosomal dominant deafness (DFNA68), autosomal recessive (AR), autosomal dominant (AD), transforming growth factor betas (TGF- $\beta$ ), Multiple epiphyseal dysplasia (MED), Porphyria hepatoerythropoietic (HEP), growth hormone (GH), Variant of unknown significance (VUS), X linked recessive (XLR), Heterozygous (het), Homozygous (hom)

\section{Declarations}

\section{Ethics approval and consent to participate}

After the approval of this study in the university's research committee and ethics in research committee of medical sciences, the study was explained to the participants and their legal guardians then a written consent was obtained from all of them to use the data for research purposes

\section{Availability of data and materials}

The datasets used and/or analyzed during the current study are available from the corresponding author on reasonable request. With the permission of the patients' legal guardians

\section{Authors Contributions}

SH N and F R designed the study, visited and carried out the treatment of the patients. SH S and H ZK performed genetic testing and analysed genetic findings. $\mathrm{K} \mathrm{K}$ designed the data collection instruments and carried out data analysis. N MKH aided in the genetic study, drafted the initial manuscript, reviewed and revised the manuscript, 
enrolled the patients in the study, collected the data and drafted the final manuscript. N GH and M GH helped in data management, revision and preparing the final manuscript

All authors approved the final manuscript as submitted and agree to be accountable for all aspects of the work. All authors approved the final manuscript as submitted and agree to be accountable for all aspects of the work.

\section{Consent to publish}

A separate informed written consent was obtained from all the patients' parents for publication purposes.

\section{Availability of data and materials}

The datasets used and analysed during the current study are available from the corresponding author in response to reasonable requests and with the permission of the patient's legal guardians.

\section{Competing interests}

The authors declare that they have no competing interests

\section{Funding}

Not Applicable ( no funds were received)

\section{Acknowledgments}

Not Applicable

\section{References}

1.Pedicelli S, Peschiaroli E, Violi E, Cianfarani SJJocripe. Controversies in the definition and treatment of idiopathic short stature (ISS). 2009;1(3):105.

2.Bryant J, Baxter L, Cave CB, Milne RJCDSR. Recombinant growth hormone for idiopathic short stature in children and adolescents. 2007(3):CD004440.

3.Seaver LH, Irons MJGiM. ACMG practice guideline: genetic evaluation of short stature. 2009;11(6):465.

4.Wit JM, Clayton PE, Rogol AD, Savage MO, Saenger PH, Cohen P. Idiopathic short stature: definition, epidemiology, and diagnostic evaluation. Growth Horm IGF Res. 2008;18(2):89-110.

5.Sisley S, Trujillo MV, Khoury J, Backeljauw PJTJop. Low incidence of pathology detection and high cost of screening in the evaluation of asymptomatic short children. $J$ Pediatr. 2013;163(4):1045-1051.

6.Lifshitz F, Moses NJJotACoN. Nutritional dwarfing: growth, dieting, and fear of obesity. J Am Coll Nutr. 1988;7(5):367-376.

7.Forchielli ML, McColl R, Walker WA, Lo CJNr. Children with congenital heart disease: a nutrition challenge. Nutr Rev. 1994;52(10):348-353.

8.Rosenfeld R, Albertsson-Wikland K, Cassorla F, et al. Diagnostic controversy: the diagnosis of childhood growth hormone deficiency revisited. J Clin Endocrinol Metab. 1995;80(5):1532-1540. 
9.Rappold G, Blum WF, Shavrikova EP, et al. Genotypes and phenotypes in children with short stature: clinical indicators of SHOX haploinsufficiency. J Med Genet. 2007;44(5):306-313.

10.Kruszka P, Porras AR, Addissie YA, et al. Noonan syndrome in diverse populations. Am J Med Genet A. 2017;173(9):2323-2334.

11.Eggermann T, Gonzalez D, Spengler S, Arslan-Kirchner M, Binder G, Schönherr NJP. Broad clinical spectrum in Silver-Russell syndrome and consequences for genetic testing in growth retardation. Pediatrics. 2009;123(5):e929e931.

12.Dauber A, Rosenfeld RG, Hirschhorn JNJTJoCE, Metabolism. Genetic evaluation of short stature. J Clin Endocrinol Metab. 2014;99(9):3080-3092.

13.Wit JM, Ranke MB, Kelnar CJJHr. The ESPE classification of paediatric endocrine diagnoses-Foreword. PLoS One. 2007;68:VII-+.

14.Lindsay R, Feldkamp M, Harris D, Robertson J, Rallison MJTJop. Utah Growth Study: growth standards and the prevalence of growth hormone deficiency. J Pediatr. 1994;125(1):29-35.

15.Chernausek SDJHrip. Whole Exome Sequencing in Short Stature: Finding Needles in the Haystack. Horm Res Paediatr. 2014;82(1):1.

16.Vassart G, Costagliola SJNRE. G protein-coupled receptors: mutations and endocrine diseases. Nat Rev Endocrinol. $2011 ; 7(6): 362$.

17.Yin Y, Li Y, Zhang WJljoms. The growth hormone secretagogue receptor: its intracellular signaling and regulation. Int J Mol Sci. 2014;15(3):4837-4855.

18.Pantel J, Legendre M, Nivot S, et al. Recessive isolated growth hormone deficiency and mutations in the ghrelin receptor. J Clin Endocrinol Metab. 2009;94(11):4334-4341.

19.van Berkel Y, Ludwig M, Van Wijk JA, Bökenkamp AJPn. Proteinuria in Dent disease: a review of the literature. Pediatr Nephrol. 2017;32(10):1851-1859.

20.Yanagida $\mathrm{H}$, Ikeoka M, Kuwajima $\mathrm{H}$, et al. A boy with Japanese Dent's disease exhibiting abnormal calcium metabolism and osseous disorder of the spine: defective megalin expression at the brushborder of renal proximal tubules. Clin Nephrol. 2004;62(4):306-312.

21.Lieske JC, Milliner DS, Beara-Lasic L, Harris P, Cogal A, Abrash E. Dent disease. In: Adam MP, Ardinger HH, Pagon RA, et al., eds. GeneReviews ${ }^{\circledR}[$ [Internet]. Seattle (WA): University of Washington, Seattle; 2017.

22.Li F, Yue Z, Xu T, et al. Dent disease in Chinese Children and findings from heterozygous mothers: Phenotypic heterogeneity, fetal growth, and 10 novel mutations. 2016;174:204-210. e201.

23.Newman WG, Friedman TB, Conway GS, Demain LA. Perrault syndrome. In: Adam MP, Ardinger HH, Pagon RA, et al., eds. GeneReviews®[Internet]. Seattle (WA): University of Washington, Seattle; 2018.

24.Nishi Y, Hamamoto K, Kajiyama M, Kawamura I, Opitz JM, Reynolds JFJAjomg. The Perrault syndrome: clinical report and review. 1988;31(3):623-629. 
25.Weegerink NJ, Schraders M, Oostrik J, et al. Genotype-phenotype correlation in DFNB8/10 families with TMPRSS3 mutations. J Assoc Res Otolaryngol. 2011;12(6):753-766.

26.Carpena NT, Lee MYJG, informatics. Genetic Hearing Loss and Gene Therapy. Genomics Inform. 2018;16(4):e20.

27.Prinos P, Costa T, Sommer A, Kilpatrick MW, Tsipouras PJHmg. A common FGFR3 gene mutation in hypochondroplasia. Hum Mol Genet. 1995;4(11):2097-2101.

28.Walker BA, Murdoch JL, McKusick VA, Langer LO, Beals RKJAjodoc. Hypochondroplasia. Am J Dis Child. 1971;122(2):95-104.

29.Elder G, Roberts AJJob, biomembranes. Uroporphyrinogen decarboxylase. J Bioenerg Biomembr. 1995;27(2):207214.

30.Kushner J, Barbuto A, Lee GJTJoci. An inherited enzymatic defect in porphyria cutanea tarda: decreased uroporphyrinogen decarboxylase activity. J Clin Invest. 1976;58(5):1089-1097.

31.De Verneuil H, Beaumont C, Deybach J, Nordmann Y, Sfar Z, Kastally RJAjohg. Enzymatic and immunological studies of uroporphyrinogen decarboxylase in familial porphyria cutanea tarda and hepatoerythropoietic porphyria. Am J Hum Genet. 1984;36(3):613.

32.Cantatore-Francis JL, Cohen-Pfeffer J, Balwani M, et al. Hepatoerythropoietic porphyria misdiagnosed as child abuse: cutaneous, arthritic, and hematologic manifestations in siblings with a novel UROD mutation. Arch Dermatol. 2010;146(5):529-533.

33.Horner ME, Alikhan A, Tintle S, Tortorelli S, Davis DMR, Hand JLJljod. Cutaneous porphyrias part I: epidemiology, pathogenesis, presentation, diagnosis, and histopathology. 2013;52(12):1464-1480.

34.Fujimoto A, Brazil JLJAjomg. Hepatoerythropoietic porphyria in a woman with short stature and deformed hands. 1992;44(4):496-499.

35.Monnier N, Romero NB, Lerale Jl, et al. An autosomal dominant congenital myopathy with cores and rods is associated with a neomutation in the RYR1 gene encoding the skeletal muscle ryanodine receptor. Hum Mol Genet. 2000;9(18):2599-2608.

36.Zullo A, Klingler W, De Sarno C, et al. Functional characterization of ryanodine receptor (RYR1) sequence variants using a metabolic assay in immortalized B-lymphocytes. 2009;30(4):E575-E590.

37.Phillips MS, Fujii J, Khanna VK, et al. The structural organization of the human skeletal muscle ryanodine receptor (RYR1) gene. Genomics. 1996;34(1):24-41.

38.Urwyler A, Deufel T, McCarthy T, West SfJBJoA. Guidelines for molecular genetic detection of susceptibility to malignant hyperthermia. Br J Anaesth. 2001;86(2):283-287.

39.Robinson R, Carpenter D, Shaw MA, Halsall J, Hopkins PJHm. Mutations in RYR1 in malignant hyperthermia and central core disease. Hum Mutat. 2006;27(10):977-989.

40.Dowling JJ, Lillis S, Amburgey K, et al. King-Denborough syndrome with and without mutations in the skeletal muscle ryanodine receptor (RYR1) gene. Neuromuscular Disorders. 2011;21(6):420-427. 
41.Stewart CR, Kahler SG, Gilchrist JM. Congenital myopathy with cleft palate and increased susceptibility to malignant hyperthermia: King syndrome? Pediatric Neurology. 1988;4(6):371-374.

42.Tobin JR, Jason DR, Challa VR, Nelson TE, Sambuughin N. Malignant Hyperthermia and Apparent Heat Stroke. JAMA. 2001;286(2):168-169.

43.Caputo V, Cianetti L, Niceta M, et al. A restricted spectrum of mutations in the SMAD4 tumor-suppressor gene underlies Myhre syndrome. 2012;90(1):161-169.

44.Schutte MJAoo. DPC4/SMAD4 gene alterations in human cancer, and their functional implications. 1999;10(suppl_4):S56-S59.

45.de Caestecker MP, Hemmati P, Larisch-Bloch S, Ajmera R, Roberts AB, Lechleider RJJJoBC. Characterization of functional domains within Smad4/DPC4. J Biol Chem. 1997;272(21):13690-13696.

46. Michot C, Le Goff C, Mahaut C, et al. Myhre and LAPS syndromes: clinical and molecular review of 32 patients. Eur J Hum Genet. 2014;22(11):1272-1277.

47.McGowan R, Gulati R, McHenry P, et al. Clinical features and respiratory complications in Myhre syndrome. 2011;54(6):e553-e559.

48.Briggs MD, Chapman KLJHm. Pseudoachondroplasia and multiple epiphyseal dysplasia: mutation review, molecular interactions, and genotype to phenotype correlations. 2002;19(5):465-478.

49.Bönnemann CG, Cox GF, Shapiro F, et al. A mutation in the alpha 3 chain of type IX collagen causes autosomal dominant multiple epiphyseal dysplasia with mild myopathy. Proc Natl Acad Sci U S A. 2000;97(3):1212-1217.

50.Chapman KL, Mortier GR, Chapman K, Loughlin J, Grant ME, Briggs MDJNg. Mutations in the region encoding the von Willebrand factor A domain of matrilin-3 are associated with multiple epiphyseal dysplasia. 2001;28(4):393.

51.Brennan M-L, Schrijver IJTJoMD. Cystic fibrosis: a review of associated phenotypes, use of molecular diagnostic approaches, genetic characteristics, progress, and dilemmas. J Mol Diagn. 2016;18(1):3-14.

\section{Tables}




\begin{tabular}{|c|c|c|c|c|c|c|c|c|}
\hline $\begin{array}{c}\text { Height } \\
\text { SD }\end{array}$ & Related condition & $\begin{array}{l}\text { Variant } \\
\text { location }\end{array}$ & $\begin{array}{l}\text { Pathogenicity } \\
\text { in literature }\end{array}$ & $\begin{array}{l}\text { Patient } \\
\text { zygosity }\end{array}$ & Variant & $\begin{array}{l}\text { Pathogenicity } \\
\text { in this study }\end{array}$ & Inheritance & Mutation \\
\hline $2.8-$ & $\begin{array}{l}\text { Isolated partial } \\
\text { GH deficiency }\end{array}$ & exone2 & VUS $^{4}$ & het $^{3}$ & $\begin{array}{l}\text { C.847>T } \\
\text { T.R283 }\end{array}$ & pathogenic & $\mathrm{AD}^{1}, \mathrm{AR}^{2}$ & $\begin{array}{c}\text { GHSR } \\
\text { NM_198407 }\end{array}$ \\
\hline $4.2-$ & Dent disease & exon14 & vUS & het & $\begin{array}{l}\text { c. } 2333 \mathrm{~T}>\mathrm{G} \\
\text { p.L778R }\end{array}$ & pathogenic & $\mathrm{XLR}^{5}$ & $\begin{array}{c}\text { CLCN5 } \\
\text { NM_001127898 }\end{array}$ \\
\hline $4-$ & Perrault syndrome & exon4 & vUS & hom $^{6}$ & c. $395 \mathrm{~T}>\mathrm{G}$ & pathogenic & $\mathrm{AR}$ & $\begin{array}{c}\text { CLPP } \\
\text { NM_006012 }\end{array}$ \\
\hline \multirow{3}{*}{$2.25-$} & DFNB8 $^{7}$ & exon5 & pathogenic & het & $\begin{array}{c}\text { c. } 266 \mathrm{G}>\mathrm{A} \\
\text { p.r89h }\end{array}$ & pathogenic & $\mathrm{AR}$ & $\begin{array}{c}\text { TMPRSS3 } \\
\text { NM_032404.2 }\end{array}$ \\
\hline & DFNA68 ${ }^{8}$ & exon3 & vUS & het & $\begin{array}{c}\text { c. } 188 \mathrm{C}>\mathrm{T} \\
\text { p.p631 }\end{array}$ & pathogenic & $\mathrm{AD}$ & $\begin{array}{c}\text { homer2 } \\
\text { NM_199330 }\end{array}$ \\
\hline & hypochondroplasia & exon8 & vUS & het & c. $992 \mathrm{G}>\mathrm{A}$ & pathogenic & $\mathrm{AD}$ & $\begin{array}{c}\text { FGFR3 } \\
\text { NM_001163213 }\end{array}$ \\
\hline $2.25-$ & HEP $^{9}$ & exon9 & pathogenic & het & $\begin{array}{l}912 \mathrm{C}>\mathrm{A} \\
\text { p.n304k }\end{array}$ & pathogenic & $\mathrm{AD}, \mathrm{AR}$ & $\begin{array}{c}\text { UROD } \\
\text { NM_000347 }\end{array}$ \\
\hline $2.25-$ & $\begin{array}{c}\text { malignant } \\
\text { hyperthermia } \\
\text { susceptibility } 1\end{array}$ & exon15 & pathogenic & het & $\begin{array}{c}. c \\
1589 G>A \\
\text { p.R530H }\end{array}$ & $\begin{array}{c}\text { Likely } \\
\text { Pathogenic }\end{array}$ & $\mathrm{AD}$ & $\begin{array}{c}\text { RYR1 } \\
\text { NM_000540 }\end{array}$ \\
\hline 3- & Myhre syndrome & exon 12 & pathogenic & het & $\begin{array}{l}\text { c. } 1498 \\
A>G \\
\text { p.1500V }\end{array}$ & pathogenic & $\mathrm{AD}$ & $\begin{array}{c}\text { SMAD4 } \\
\text { NM_005359 }\end{array}$ \\
\hline $2.25-$ & MED $^{10}$ & $\begin{array}{c}\text { exone } \\
18\end{array}$ & pathogenic & het & $\begin{array}{l}\text { c. } 920 \mathrm{G}>\mathrm{A} \\
\text { p.G307D }\end{array}$ & pathogenic & $\mathrm{AD}$ & $\begin{array}{c}\text { COL9A3 } \\
\text { NM_001853 }\end{array}$ \\
\hline $4.2-$ & Cystic fibrosis & exon11 & pathogenic & het & $\begin{array}{c}\text { c. } 1397 \mathrm{C}>\mathrm{G} \\
\text { p.s466 }\end{array}$ & pathogenic & $\mathrm{AR}$ & $\begin{array}{c}\text { CFTR } \\
\text { NM_000492 }\end{array}$ \\
\hline
\end{tabular}




\begin{tabular}{|c|c|c|}
\hline \multicolumn{2}{|c|}{ Table 2 } & mutation \\
\hline Hormone therapy response & Related condition & GHSR \\
\hline excellent & Isolated partial GH deficiency & CLCN5 \\
\hline poor & Perrault syndrome & CLPP \\
\hline poor & hypochondroplasia & FGFR3 \\
\hline weak & HEP ${ }^{1}$ & UROD \\
\hline poor & malignant hyperthermia susceptibility 1 & RYR1 \\
\hline good & Myhre syndrome & SMAD4 \\
\hline weak & MED & COL9A3 \\
\hline weak & Cystic fibrosis & CFTR \\
\hline Excellent & & \\
\hline
\end{tabular}

